\title{
¿Aprender tsotsil? Experiencia con niños \\ de una primaria urbana en San Cristóbal
}

\author{
Learning tsotsil? Experience with children \\ in an elementary school in San Cristobal
}

\section{Alejandra Rodríguez Torres ${ }^{1}$ \\ María Elena Fernández Galán Rodríguez ${ }^{2}$}

Resumen: San Cristóbal es una ciudad donde convergen varias culturas, situación que presenta un reto a la enseñanza y a la convivencia escolar. Este trabajo se basa en una experiencia con niños de familias migrantes del estado de Chiapas, México, de cuarto año de primaria. El propósito inicial consistió en fomentar el respeto a la diversidad cultural a través de la lectoescritura en tsotsil y español. Para profundizar en la percepción de los niños sobre la adquisición de la lectoescritura en tsotsil y los valores se trata de analizar lo que ellos mismos han escrito. Contamos para esta aproximación con las cartas dirigidas a la

\footnotetext{
${ }^{1}$ Licenciada en bibliotecología y especialista en Procesos Culturales Lecto-escritores, Instituto de Estudios Indígenas Unach. Intereses: lectoescritura, lenguas indígenas y bibliotecología. Correo electrónico: lunabyte@hotmail.com

${ }^{2}$ Maestra en bibliotecología, Instituto de Estudios Indígenas Unach. Intereses: lectoescritura, lenguas indígenas, información. Correo electrónico: bibliotecaiei@hotmail.com Fecha de recepción: 0307 14; Fecha de aceptación: 171014.
} 


\section{A. Rodríguez y $M^{a}$ Elena Fernández ¿Aprender tsotsil? Experiencia...}

persona encargada del apoyo financiero en las cuales los alumnos nos dan a conocer su opinión sobre los talleres impartidos, y con una serie de cuentos escritos libremente por ellos mismos en donde se reflejan sus valores e intereses.

Palabras clave: lectoescritura, diversidad cultural, educación.

Abstract: San Cristobal is a multicultural city, which creates a challenge for teaching and building social harmony in school. The present work is based on a project with migrant fourth grade children in an elementary school in the northern periphery of San Cristobal, Mexico. The main purpose was to encourage the children to respect cultural diversity through a reading and writing workshop in Tsotsil and Spanish. To understand the life values of the children and what they thought about the acquisition of literacy in Tsotsil, we will analyze what they themselves have written, including letters the children wrote to the person in charge of resources in which they express their opinions about the workshops, and a series of stories where they reflect on their values and interests.

Keywords: literacy, cultural diversity, education. 


\section{A. Rodríguez y $M^{a}$ Elena Fernández ¿Aprender tsotsil? Experiencia...}

\section{Introducción}

Pertenecer a una cultura diferente a la nacional presenta un conflicto en el proceso de aprender a leer y escribir. Solamente hay que revisar los programas educativos y los libros de texto para notar la exclusión de los hablantes de lenguas minoritarias así como de todos los hispanohablantes fuera del centro de México. La escuela tiene como misión legitimar la "cultura nacional". La marginación de comunidades locales en el sistema educativo no está circunscrita a lo lingüístico, sino que abarca también el contexto histórico y sociocultural de cada grupo, por eso las políticas en educación tendrían que organizarse dentro de los procesos de pensamiento y comunicación de cada cultura local. Las intensas migraciones recientes a San Cristóbal significan el encuentro de varias culturas; el diverso origen manifiesta diferencias en el habla, la vestimenta, las creencias, la alimentación y la organización social. Los niños que ingresan a las escuelas de la periferia reflejan esta diferencia cultural, lo que representa un reto a la enseñanza y a la convivencia entre los maestros y los alumnos, así como entre estos últimos. La imposición de la cultura nacional como legítima empieza por la escuela, porque ser diferente se contrapone a la "nación”, excluye las culturas locales. Las clases inician la semana con el himno nacional. 


\section{A. Rodríguez y $M^{a}$ Elena Fernández ¿Aprender tsotsil? Experiencia...}

El tsotsil es la lengua indígena más hablada en la ciudad, ${ }^{3}$ aun cuando su lectura y escritura no se conocen o no se practican. Los idiomas nativos viven una situación de inequidad frente al español, lo cual propicia la discriminación de sus hablantes. Lo que no se conoce se ignora o se desprecia, es por ello la necesidad de que hablantes de castellano tengan oportunidad de aprender una lengua indígena como parte de su formación de vida en un espacio urbano diverso. Es importante señalar que escribir las lenguas amerindias les permite la sobrevivencia por el prestigio que otorga la palabra escrita, sin escritura es además condenarlas al olvido por la falta de registros impresos.

Para entender la problemática de la educación en un contexto de encuentros culturales, el presente artículo aborda temas como la diversidad cultural de la ciudad además de describir la periferia norte de San Cristóbal, lugar en el que se localiza la escuela primaria donde se realizó el taller. Posteriormente, se analizan los conceptos interculturalidad y multiculturalismo, así como su relación con el discurso educativo. Asimismo, se describen las actividades desarrolladas durante la actividad. Por último, se incluye el análisis de los intereses de los niños reflejados en sus cuentos y su opinión sobre esta intervención educativa manifestados en sus cartas.

\footnotetext{
${ }^{3}$ Según el Censo de Población y Vivienda de Inegi (2010) en sus tabulados de 5 años y más sobre hablantes de lengua indígena en San Cristóbal, del total de la población con estas características (59,943 personas), el tsotsil es la lengua más hablada con $72.23 \%$, seguido del tseltal $(25.75 \%)$ y el chol $(0.95 \%)$.
} 


\section{La diversidad cultural de la ciudad}

La situación urbana lleva implícita una densidad social y demográfica donde la heterogeneidad y la diferencia redundan en actitudes, valores e instituciones mediante las cuales se expresa la modernidad particular de cada ciudad. Por su condición de espacio definido y rodeado, protegido y coherente, la ciudad inventa, cambia, renueva y revoluciona. Las personas procedentes de zonas rurales son vistas como tradicionales y poco adaptadas a la vida moderna, por lo que cuando llegan del campo los migrantes tratan de diluirse e imitar la vida de los citadinos.

La ciudad de San Cristóbal es un lugar plural y complejo donde se encuentran indígenas y personas procedentes de otros puntos del país y también de varios países extranjeros. La mayor parte de los trabajos publicados giran en torno a la presencia indígena, sin embargo la ciudad se ha convertido en un lugar cosmopolita, baste ver los censos para conocer cómo se conforma la población. ${ }^{4}$ San Cristóbal pasó de ser un lugar de difícil acceso antes de 1950 a estar comunicado por carreteras, de ser un pueblo desconocido a ubicarse en el centro de la atención mundial a raíz del levantamiento zapatista en 1994.

\footnotetext{
${ }^{4}$ De acuerdo con el Censo de Población y Vivienda Inegi (2010) se observa que las personas que viven en San Cristóbal y que son de otras entidades federativas llegan principalmente del Distrito Federal (31.33\% de la población total), 14.07\% de Veracruz, 10.38\% de Oaxaca y $8.24 \%$ de Tabasco. En relación con los extranjeros residentes en esta ciudad, Inegi (2010) señala que provienen en su mayoría de Estados Unidos ( $0.103 \%$ de la población total de la ciudad), $0.037 \%$ de Guatemala, $0.027 \%$ de España, $0.020 \%$ de Francia y $0.016 \%$ de Alemania. No obstante, el censo cuenta además con registros de residentes originarios de Cuba, Colombia, Japón, China, Corea del Sur, Marruecos, Australia, entre otros.
} 


\section{A. Rodríguez y $M^{a}$ Elena Fernández ¿Aprender tsotsil? Experiencia...}

Un buen número de migrantes temporales y definitivos han transformado en pocos ańos el aspecto de la ciudad. A mediados del siglo XX llegaron muchas más personas que procedían de comunidades indígenas así como de algunos países europeos y americanos. Los primeros migrantes indígenas generalmente arribaron como sirvientes, en tanto que los primeros migrantes extranjeros llegaron buscando una manera más cercana a la naturaleza, para producir arte o literatura, o estudiar principalmente a los grupos indígenas. Desde los años 70 se abrieron muchos espacios académicos para desarrollar investigación en comunidades aledañas. A partir de los 90 se incrementó el turismo, lo que centuplicó las posibilidades de trabajo de todos los oficios y profesiones: construcción, servicios, transportes, alimentos, hospitales, entre otros, esto propició la llegada de mayor número de indígenas, nacionales y extranjeros. Desde 1994 se establecieron muchas organizaciones no gubernamentales nacionales e internacionales que iniciaron actividades a raíz de los conflictos en Guatemala y el levantamiento neozapatista. En el año 2000 se iniciaron labores en nuevas universidades para ofrecer varios programas, lo que atrajo mayor número de estudiantes rurales.

Esta convivencia entre grupos de ladinos, ${ }^{5}$ nacionales de otros lugares y extranjeros, ha contribuido a transformar algunas formas de vida local, asimismo se han modificado los espacios de reunión, los gustos arquitectónicos y también se dieron cambios alimenticios y de salud. Por otro lado se trastocaron patrones de matrimonio debido a las oportunidades de encuentros entre ${ }^{5}$ En Chiapas se usa la palabra ladino o ladina para referirse a las personas que no son indígenas, de parte de los indígenas se les dice kaxlanes. 


\section{A. Rodríguez y $M^{a}$ Elena Fernández ¿Aprender tsotsil? Experiencia...}

personas llegadas de diversos rumbos. En todos estos cambios han influido los medios masivos de comunicación, radio, televisión, internet y los celulares, que constituyen uno de los factores que fomentan el cambio sociocultural. Además de los indígenas, se pueden distinguir extranjeros avecindados que se reconocen por su acento: grupos numerosos de italianos, americanos, japoneses y franceses, muchos pertenecen a ong internacionales, otros han abierto negocios como restoranes de su particular comida tradicional, venta de ámbar y artesanías, y varios de ellos han introducido nuevos patrones de modelos textiles y de adornos.

Por otros motivos, en la ciudad se han multiplicado las nuevas adscripciones religiosas, que coexisten con los católicos: Iglesias nuevas y tradicionales, credos diversos como Testigos de Jehová, mormones, budistas, musulmanes y judíos. Los templos están dispersos en la periferia y la mezquita se puede distinguir por la altura de su minarete. Asimismo podemos mencionar la proliferación de nuevas formas espirituales new age donde participan una enorme cantidad de extranjeros, indígenas y connacionales en espacios dedicados para estos encuentros. Muchos de estos encuentros espirituales están relacionados con la salud.

En San Cristóbal existe desde hace poco una diversificación de venta de productos alimenticios que abarca todo tipo de panaderías y pastelerías, de verduras y frutas, orgánicos, naturistas, y también una enorme selección de productos empaquetados de la gran ciudad. Esto ha contribuido al enriquecimiento de la alimentación de los habitantes, ya 


\section{A. Rodríguez y $M^{a}$ Elena Fernández ¿Aprender tsotsil? Experiencia...}

que cuentan con mayor variedad de alimentos, no siempre para mejorar la salud.

Se puede observar una enorme diversidad de vestimentas, extranjeros con peinados y trajes de todo tipo, nacionales que siguen más o menos la moda de la televisión, y sobre todo se puede ver la indumentaria tradicional de todos los grupos originarios de Chiapas. La presencia de mujeres indígenas que usan sus huipiles y faldas — enredos— resalta en el panorama multicultural de San Cristóbal de Las Casas como un aspecto atrayente para los turistas.

En cuanto a los cambios arquitectónicos, junto al barroco de las iglesias y el neoclásico de algunas construcciones civiles, las casas habitación del centro conservan todavía el estilo colonial de adobe y teja, puertas de madera, llamadores y herrería tradicionales; estos modelos de viviendas ya no se observan en la periferia. Se ha experimentado una gran transformación de casas en comercios de la mayor parte del centro histórico que ha cambiado por completo la dinámica de la ciudad; la vida citadina ya no termina a las 8 de la noche sino continúa hasta altas horas de la madrugada en la enorme cantidad de centros nocturnos. Las casas nuevas son de block y colado de cemento. Los templos coloniales no tienen parecido con las construcciones de los nuevos cultos. La mezquita es de un diseño estilo árabe.

\section{La periferia de San Cristóbal}

Las familias migrantes con menores recursos se asientan generalmente en espacios no ocupados, en las orillas de la ciudad. La periferia de San 


\section{A. Rodríguez y $M^{a}$ Elena Fernández ¿Aprender tsotsil? Experiencia...}

Cristóbal es un espacio semiurbano todavía arbolado con algunos sembradíos dispersos; culturalmente las familias conservan, generalmente, el concepto de comunidad, así como prácticas de las curaciones, cultivos y cuidado de los borregos. La mitad de la población de San Cristóbal es de origen indígena en primera o segunda generación, conviven tsotsiles, tseltales, algunos choles y tojolabales agrupados por colonias homogéneas o mixtas. ${ }^{6}$ También han emigrado a la ciudad ladinos del estado, muchos de estos grupos pierden los lazos comunitarios que existían en sus pueblos de origen.

No se puede hablar de los asentamientos en la periferia como un espacio homogéneo, cada colonia presenta sus particularidades; en este caso nos referiremos a la zona norte, que se distingue por la presencia de un gran número de tsotsiles, sus casas pasaron de ser de madera y cartón a casas de block; los musulmanes tienen una presencia particular, ya que llevan vestimentas diferentes, otro tipo de alimentación y practican nuevos oficios como carpintería y panadería. En la zona norte se estableció una reserva natural protegida en las antiguas ruinas de Moxviquil, asentamiento prehispánico, junto a la vieja colonia Ojo de Agua. Otro punto que llama la atención es Peje de Oro, que conserva en ruinas el antiguo molino y un puente techado. La orillada de la Colonia 31 de Marzo es una mezcla arquitectónica por la variedad de situaciones económicas de las familias asentadas allí. ${ }^{7}$

\footnotetext{
${ }^{6}$ La mayor parte de los trabajos sobre la población de San Cristóbal (Hvostoff, 2009; Rus, 2009; Paniagua, 2014) hace referencia a la presencia indígena en contraposición de la población ladina. Sin embargo existen otros grupos de nacionales y extranjeros que conforman y contribuyen a la diversidad de la ciudad.

${ }^{7}$ Los antiguos habitantes del centro histórico se han mudado a otros espacios periféricos muy diferentes a los que ocupan los migrantes. Sus casas antiguas se han convertido en hoteles o restoranes.
} 
En una ciudad cosmopolita como San Cristóbal se distinguen los grupos por su origen lingüístico. ${ }^{8}$ Además de que se hablan varias lenguas indígenas, también hay variedad de acentos y vocabularios en español de otras regiones, palabras que se usan en otros sentidos; por otro lado, se escucha con frecuencia en la calle hablar inglés y otras lenguas extranjeras (Fernández Galán, 2010). Los niños de todos los orígenes crecen en la idea y práctica sobre el predominio del castellano, esta circunstancia ha permanecido en la conciencia de los lugareños desde la fundación de la ciudad.

La intención de llevar a cabo un taller de lectoescritura en tsotsil es buscar una estrategia que dé valor a las lenguas indígenas tanto entre los hablantes de las mismas como hispanohablantes, ya que ambos grupos discriminan las lenguas aborígenes. La llamada educación bilingüe no ha logrado que los hablantes se conviertan ni en defensores ni en escritores de sus lenguas, basta ver las escasas publicaciones en lenguas indígenas. La educación bilingüe ha sido suficientemente estudiada en Chiapas aun cuando faltan trabajos para contextos urbanos, sin embargo para fines de esta experiencia sería demasiado extenso abordar el tema. ${ }^{?}$

\footnotetext{
${ }^{8}$ En los tabulados de Inegi (2010) correspondientes a la población de 5 años y más, se registraron estos hablantes de lenguas amerindias en el municipio de San Cristóbal de Las Casas: aguacateco 1 , chinanteco 1 , chol 571, chontal 2, chuj 1, cora 1, huave 1, kanjobal, 10, mame 18 , maya 16 , mazateco 4 , mixe 38 , mixteco 6 , náhuatl 34 , otomí 6 , purépecha 3 , tarahumara 1 , tojolabal 41, totonaca 1 , tseltal 15440 , tsotsil 43302 , zapoteco 83 y zoque 83 .

${ }^{9} \mathrm{Sin}$ embargo, dentro de estos pocos trabajos realizados en escuelas bilingües en la periferia de San Cristóbal encontramos la investigación de Pons (2001) acerca de las actitudes que asumen los jóvenes tseltales hacia el uso de su lengua materna a partir de su incorporación en los espacios escolares de nivel secundaria.
} 


\section{A. Rodríguez y $M^{a}$ Elena Fernández ¿Aprender tsotsil? Experiencia...}

Enseñar a escribir y a disfrutar de la lectura en tsotsil puede permitir que trascienda una lengua cotidiana, ayuda a formar un corpus literario que pueda asegurar su prestigio, conservación, supervivencia a la vez que mostrar a los no hablantes que existe un universo diferente que vale la pena conocer.

\section{Interculturalidad y educación}

La interculturalidad, como paradigma, se ha colocado dentro del discurso oficial y ocupa un lugar importante en las políticas culturales actuales. García Canclini (2004) sintetiza que los estudios sobre la interculturalidad han variado. Por ejemplo los anglosajones se han concentrado en la comunicación interculturali: ${ }^{10}$ en Francia y otros países interesados por la integración de los migrantes de otros continentes, sobresale la orientación educativa que plantea los problemas de la interculturalidad como la adaptación de la lengua y la cultura dominante; en América Latina predomina la consideración de lo intercultural como relaciones interétnicas. En cualquiera de los casos, según este autor, la interculturalidad remite a la "confrontación y el entrelazamiento, a lo que sucede cuando los grupos entran en relaciones e intercambios". Además, sostiene que las concepciones multiculturales admiten la diversidad de culturas, recalcando sus diferencias y proponiendo políticas relativistas de respeto que a menudo refuerzan la segregación. Cabe señalar que tanto los términos multiculturalidad como interculturalidad implican "dos modos de producción de lo social, ya que el primero supone

\footnotetext{
${ }^{10}$ Entendida en un primer momento como relaciones interpersonales entre miembros de una misma sociedad o de culturas diferentes, y luego abarcando las comunicaciones a través de los medios masivos entre sociedades distintas.
} 
la aceptación de lo heterogéneo, lo diferente; mientras que el segundo término alude que "los diferentes son lo que son en relaciones de negociación, conflicto y préstamos recíprocos".

El análisis conceptual nos sirve para aterrizar en la situación de América Latina, incluyendo México, donde la enseñanza bilingüe suele a menudo llamarse "educación intercultural". Si bien es cierto que la cuestión lingüística tiene que ver con la interculturalidad, no es suficiente para que exista una educación de este tipo. Por ello, la "educación bilingüe” propuesta por el Estado hasta ahora es un caso específico de multiculturalismo, porque aunque exista una formación paralela en ambos idiomas, no significa que exista un diálogo entre estos dos universos culturales. En México, la educación bilingüe se ha utilizado como una estrategia para la castellanización. ${ }^{11}$

En este sentido, la función que ha tenido el sistema educativo ha sido contribuir a la homogeneización de la población para tratar de "eliminar" las diferencias entre sus ciudadanos. Como indica Ferreiro (1996: 4), "la tendencia principal [por parte del sistema educativo y del gobierno] fue equiparar igualdad con homogeneidad". En Chiapas se propone la interculturalidad como política transversal del gobierno actual de Manuel Velasco Coello, y en

\footnotetext{
${ }^{11}$ De acuerdo con Freedson y Pérez (1999), los estudios cualitativos realizados en Chiapas y en otros estados de México, durante las últimas tres décadas (Modiano, 1974; Aguirre Beltrán, 1983; y otros) demuestran el limitado uso de las lenguas indígenas en las escuelas bilingües, a pesar de que desde los años 50 existen lineamientos para el uso de éstas como medio de instrucción. Los principios psicopedagógicos que orientan la educación bilingüe se basan en la consolidación de la lectoescritura en la lengua indígena como fundamento para aprender de mejor manera los contenidos. Sin embargo, la lengua materna es considerada como un puente al español, el cual se introduce gradualmente a través de la traducción, repetición y la alternancia de ambos idiomas. La lectoescritura en la lengua indígena, según estos autores, recibe un tratamiento superficial o, en su caso, nulo.
} 


\section{A. Rodríguez y $M^{a}$ Elena Fernández ¿Aprender tsotsil? Experiencia...}

cuanto a la educación básica indica que el objetivo de su gestión es promover una educación de calidad, y una de las estrategias para llevarla a cabo es atender la diversidad con equidad e interculturalidad en las escuelas del estado (Gobierno del estado de Chiapas, 2013).

Como se ha observado, si bien en el discurso nacional y estatal toman en cuenta la interculturalidad, la educación intercultural queda relegada a procurar una mejor convivencia y solamente respetar y apreciar la diversidad cultural, en ningún momento se ofrece que dentro del sistema educativo se adecue a los intereses de las culturas diferentes a la nacional. Lo intercultural está solamente relacionado con las estrategias de educación para los grupos de lengua aborigen. El Estado debe reconocer y asumir que la diversidad no sólo se circunscribe a los indígenas.

Estamos de acuerdo con Ferreiro (1996) cuando dice que es indispensable instrumentar didácticamente a la escuela para trabajar con la diversidad y que es posible transformarla en una ventaja pedagógica, por tanto cada comunidad debe tener su propia dinámica, lo que la hace diferente a las otras, ya que como argumenta Bertely (2013: 143):

La apropiación local de la escolarización oficial implica que los sujetos sociales y las comunidades humanas en general, sean indígenas o no, generan culturas escolares contextualizadas y, en este sentido, construyen significados, usos escolares y prácticas escolares particulares y distintivos. Los procesos de apropiación escolar son, en términos estrictos, de naturaleza situada. 


\section{A. Rodríguez y $M^{a}$ Elena Fernández ¿Aprender tsotsil? Experiencia...}

La educación en la diversidad necesita basarse en fundamentos socioculturales y psicopedagógicos y proponerse desarrollar al ser humano en su diversidad personal y grupal. Las estrategias, como señala Fornet (2002, citado por Saldívar, 2005), necesitan orientarse para "compensar/suprimir, así como compartir/estimular/respetar las diferencias y las desigualdades" que se generan en la escuela. Lo anterior propiciaría la implicación en todos los ámbitos de la acción educativa, tanto a nivel de centro escolar, de equipo docente y de aula.

\section{La lectoescritura en la diversidad: actividades del taller}

\section{La escuela primaria}

La primera idea fue trabajar en un contexto de primaria bilingüe periférica, sin embargo los maestros la rechazaron argumentando que ellos sabían hacerlo mejor y que no necesitaban este tipo de talleres donde se fomentara el leer y escribir en tsotsil. Por ello, se abrió la posibilidad de que el taller se realizara en una escuela primaria estatal ${ }^{12}$ —que no pertenece al sistema bilingüe—-, ubicada en la colonia de mismo nombre en la periferia norte oriente de la ciudad, adonde acuden niños de diverso origen con una fuerte presencia indígena.

La directora de la escuela señaló que del grupo de veintiséis, ocho niños tenían dificultades para leer y escribir, lo cual representó un reto inicial. Esta escuela se ha caracterizado por aceptar a niños que, por diversas circunstancias, no han sido aceptados en otras instituciones educativas. Por este

\footnotetext{
${ }^{12}$ Se omite el nombre de la escuela por cuestiones de privacidad y seguridad.
} 


\section{A. Rodríguez y $M^{a}$ Elena Fernández ¿Aprender tsotsil? Experiencia...}

motivo, se pueden encontrar alumnos que viven en otras colonias y barrios. ${ }^{13}$ El centro escolar cuenta con seis grupos, no posee sala de cómputo y los libros que conforman la biblioteca escolar se localizan en la dirección por falta de espacios. La plantilla docente está integrada por ocho maestros, ninguno bilingüe, seis frente a grupo, un profesor de educación física y otro de educación artística.

\section{Facilitadores}

Es importante señalar que el equipo de facilitadores era diverso y cada integrante enriqueció el taller con sus experiencias. El taller fue facilitado por María Elena Fernández Galán, coordinadora de las actividades; Alejandra Rodríguez; una persona hablante de tsotsil de Chenalhó, y una maestra estadounidense hablante de tsotsil. Eventualmente se contó con el apoyo de pasantes de servicio social en la biblioteca de IEI Unach, panameños del grupo étnico kuna.

\section{Metodología}

Para el desarrollo del taller se retomó parte de la propuesta de Clemente Linuesa (2008), quien sostiene que la enseñanza de la lectoescritura debe cubrir cuatro dimensiones, las cuales se interrelacionan entre sí y son las siguientes:

- Sistemas de representación: la escritura como sistema de símbolos, incluye juegos simbólicos que toman en cuentan los gestos y el dibujo

\footnotetext{
${ }^{13}$ Esto no es común, ya que las escuelas que se ubican en el centro de San Cristóbal dan preferencia a niños que viven cerca del centro escolar y que tienen hermanos inscritos en ese plantel.
} 


\section{A. Rodríguez y $M^{a}$ Elena Fernández ¿Aprender tsotsil? Experiencia...}

como sistema de representación simbólica. Ejemplos de ello fueron el uso del dibujo y el teatro.

- Funcionalidad de lo escrito: con ejercicios que desarrollan las funciones comunicativa, informativa, estética y creativa. Por ejemplo, las tarjetas de navidad para sus padres y las cartas, la escritura de cuentos propios, los carteles de ciencias.

- Comprensión lectora: activación de conocimientos previos —explicar lo que se va a leer, qué se sabe sobre el tema, relacionar vivencias y experiencias - y actividades asociadas con la interpretación del texto - vocabulario nuevo, preguntas acerca del texto- $y$ conocimiento sobre lo leído — reconocer el esquema del texto, por ejemplo los cuentos y las cartas; construir escritos dando expresiones y formatos.

- Aprendizaje del código: análisis metalingüístico, reglas de correspondencia grafema-fonema.

Es importante señalar que la última dimensión no fue trabajada como parte del taller.

También retomamos las aportaciones de Bruner (1991, citado por Clemente, 2008), el cual señala la importancia de la narración, ya que es la modalidad discursiva que mejor comprende el niño por ser la forma de expresión habitual y más propia de su entorno, así como una forma de socialización. El relatar historias y escucharlas es un momento central en la educación escolar, ya que puede llevar al aprendizaje de lo escrito debido a que permite 


\section{A. Rodríguez y $M^{a}$ Elena Fernández ¿Aprender tsotsil? Experiencia...}

una relación entre el niño y el texto, una especie de diálogo en donde se planteen dudas, incluso cuestionen la propia historia que se narre. Asimismo, en palabras de Bruner, la narración "es un momento del complejo proceso de hominización del ser humano: educación del sentimiento del deseo, de la imaginación y de la razón”, en definitiva, permite explorar su manera de ver el mundo y cómo la construye. Esto se retoma especialmente para el análisis de los cuentos escritos por los nińos durante el taller.

\section{El grupo}

$\mathrm{Al}$ iniciar el taller en noviembre de 2013, el grupo estaba compuesto por veintiséis alumnos, de los cuales dieciocho eran niñas y el resto niños, cuyos padres migraron a la ciudad provenientes de Tenejapa, El Romerillo (Chamula), Huixtán y Pantelhó. En cuanto a la lengua, ocho hablaban tsotsil, cinco tseltal, seis eran de origen indígena pero sólo hablaban castellano y el resto era mestizo. Cabe añadir que las condiciones socioeconómicas de los niños eran desiguales, tres de ellos llevaban celulares a la escuela, no todos usaban el uniforme e incluso varios iban sin desayunar y sin dinero para comprar comida durante el receso. Algunos niños trabajaban por las tardes o los fines de semana.

En cuanto a la dinámica del grupo, el maestro nos había comentado que tres niños y una niña tenían problemas de conducta, y que habitualmente eran acusados por agresión tanto verbal como física a sus compañeros de clase. También los niños se quejaban con las facilitadoras del comportamiento de algunos de sus compañeros. En el primer encuentro se preguntó quiénes 


\section{A. Rodríguez y $M^{a}$ Elena Fernández ¿Aprender tsotsil? Experiencia...}

hablaban una lengua indígena y sólo una niña hablante de tsotsil de Chamula alzó la mano. Conforme avanzaba el taller, los niños se animaron a decir qué lengua materna hablaban.

Figura 1: Poesía escrita durante el taller

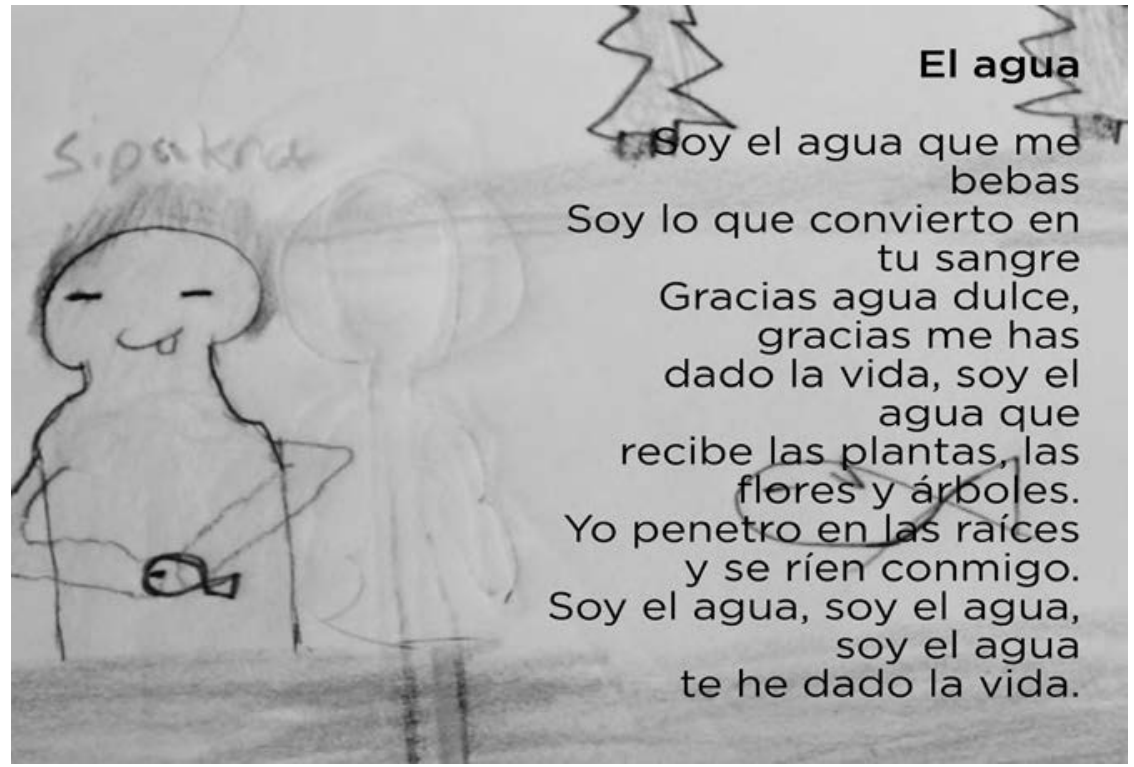

Fuente: Alejandra Rodríguez y María Elena Fernández Galán, 2013. 


\section{A. Rodríguez y $M^{a}$ Elena Fernández ¿Aprender tsotsil? Experiencia...}

\section{El taller: desarrollo, actividades y experiencias}

Fue necesario plantear al grupo que el taller sería un espacio de respeto en donde todos eran iguales y que las facilitadoras más que ser maestras eran amigas. Asimismo, se les propuso aprender a leer y a escribir tanto en español como en tsotsil, animándoles a conocer una forma distinta de nombrar el mundo. De igual manera, se les prometió publicar sus escritos.

\section{Forma de trabajo}

El taller tuvo una duración total de 180 horas. En un primer momento, se formó un grupo de niños hablantes de lengua indígena y otro de niños hispanohablantes; una facilitadora trabajaría las actividades de fomento a la lectura en español mientras que la otra trabajaría en la enseñanza del tsotsil. Asumir esta postura fue un error si queríamos lograr relaciones interculturales horizontales, debido a que marcaba aún más las diferencias entre los niños. Los alumnos que hablaban castellano no estaban de acuerdo en aprender tsotsil e incluso mostraban actitudes de rechazo. También los propios niños indígenas negaban su origen y no querían pertenecer a ese grupo. Inclusive los niños nos pidieron que se les enseñara inglés. Convenimos en que las actividades del taller fueran para todo el grupo y alternaríamos lecciones de tsotsil con las de castellano. Fue fundamental permitir a los nińos hablar espontáneamente y que comunicaran sus experiencias sobre temas significativos para ellos. Con lo cual se logró que 


\section{A. Rodríguez y $M^{a}$ Elena Fernández ¿Aprender tsotsil? Experiencia...}

las facilitadoras conocieran parte de las expectativas, emociones y vivencias de los alumnos.

Por otro lado, la imaginación y la creatividad se incorporaron como ejes que articularon las actividades, ya que para desarrollar el pensamiento lógico que requiere el proceso lectoescritor no hay necesidad de sacrificarlas, al contrario, es necesario establecer condiciones para que el niño pueda hacer uso de ellas. ${ }^{14}$

\section{Prácticas de lectura y escritura}

Para trabajar las actividades de lectura se seleccionaron cuentos cortos con historias de la tradición oral tsotsil —materiales bilingües tsotsil-español—. Dentro de los pocos textos publicados, en la literatura indígena casi no existen escritos creados ex profeso para los nińos, lo cual representó una dificultad; aún así, se optó por relatos centrados en valores como la amistad, la honestidad, la solidaridad y el respeto.

Antes de la lectura, fue importante abrir un espacio previo en donde se compartieron entre nińos y facilitadoras situaciones y vivencias personales relacionadas con las presentadas en las historias. Se compararon con el grupo las experiencias similares para establecer conexiones con los textos, de manera

\footnotetext{
${ }^{14}$ En este sentido, Rodari (1999) apunta que no hay que sorprenderse de que la imaginación en las escuelas sea considerada como "un pariente pobre", que poco puede aportar al aprendizaje de los nińos, respecto a la atención y a la memoria; ya que "escuchar con paciencia y recordar con escrúpulo constituyen todavía la característica del estudiante modelo; que es el más cómodo y dócil". Vygotski, citado por este mismo autor (Rodari, 1999: 199), sostiene que "se necesita que el niño pueda crecer en un ambiente rico de impulsos y estímulos en todas direcciones, para alimentar así su imaginación y aplicarla a tareas adecuadas que refuercen sus estructuras y amplíen sus horizontes".
} 


\section{A. Rodríguez y $M^{a}$ Elena Fernández ¿Aprender tsotsil? Experiencia...}

que tuvieran mayor significado. Para abrir el apetito a la imaginación se inició la escritura con la lectura de imágenes, cada niño escogería una imagen de alguna revista y a partir de ella escribiría acerca de un viaje imaginario. Asimismo se realizaron actividades de comprensión de textos expresadas a través de dibujos y pinturas (Fernández Galán, 2013).

Además, se sugirieron diferentes temas para escribir, como los sueños, reflexiones acerca de lo que los hacía felices, qué querían ser de adultos e interpretaciones sobre fenómenos naturales como el arco iris. También realizaron collages a partir de recortes de revistas con la idea de construir una historia para ser escrita. Se utilizaron estrategias como el modelado de figuras de plastilina, lo cual facilitó la descripción de los personajes de los cuentos, así como escuchar música, lo que permitió crear ambientes que propiciaron la escritura de géneros específicos. Los ejercicios también se orientaron a propósitos prácticos de comunicación y sobre todo que pudieran ser de interés para los propios niños, como las cartas a sus padres y las tarjetas de navidad y felicitaciones. De igual manera, los alumnos aprendieron a usar las computadoras donadas a la escuela por el IEI, para la mayoría fue su primera experiencia; esta actividad tuvo gran éxito.

\section{Lecciones en tsotsil}

Convencer a los niños de que aprender a leer y a escribir en tsotsil era tan importante como aprender el español no fue fácil, particularmente para los hispanohablantes. La primera reacción de los nińos fue de gestos de rechazo. Por otro lado, los mismos 


\section{A. Rodríguez y $M^{a}$ Elena Fernández ¿Aprender tsotsil? Experiencia...}

niños de origen indígena no hablaban su lengua dentro de la escuela porque los otros se burlaban de ellos, incluyendo a los hablantes de los mismos idiomas. Resultó difícil crear un ambiente de respeto, ya que dentro del taller los niños se mofaban de sus compañeros cuando participaban en la sesiones de tsotsil, e incluso hubo una agresión de un nińo hacia la facilitadora hablante de este idioma.

Las lecciones se orientaron a conocer palabras habladas y escritas. ${ }^{15}$ Se leyeron cuentos cortos para familiarizarse con los sonidos. Fue muy interesante que los alumnos hablantes de tseltal también compartieran vocabulario en su propio idioma. Se establecieron diálogos de intercambio de saberes entre los niños y los facilitadores, esto contribuyó a dar importancia a los conocimientos previos del grupo.

En lo que concierne a la redacción de cuentos, aquellos que desearon escribirlos en tsotsil pudieron solicitar el apoyo de las facilitadoras. Solamente dos niñas tsotsiles y una tseltal escribieron sus cuentos y adivinanzas en su propio idioma, así como una nińa mestiza pidió que su cuento estuviera escrito en tsotsil.

\section{Discriminación lingüística dentro del aula: logros y retos}

Como se señaló en el apartado anterior, no fue fácil convencer a los niños para que aprendieran tsotsil. Este rechazo hacia la lengua indígena no solo provenía de los niños ladinos, sino que también era manifestado por los propios niños indígenas. Las niñas nos compartieron que preferían no ${ }^{15}$ Se enseñó a todo el grupo vocabulario sobre las partes del cuerpo, los colores, los elementos de la naturaleza, los animales, la familia, los alimentos, entre otros temas. 


\section{A. Rodríguez y $M^{a}$ Elena Fernández ¿Aprender tsotsil? Experiencia...}

hablar en tsotsil porque sus compañeros se reían de ellas, las imitaban en tono de burla.

Por ejemplo, durante la sesión en tsotsil sobre las partes del cuerpo humano, dos niños tsotsiles no quisieron pronunciar palabra, a pesar de que sabían cómo hacerlo. Otra niña ladina dijo que no le gustaba escribir en este idioma y hacía gestos de rechazo y disgusto. Cuatro niños — dos ladinas y dos indígenas - se negaron a escribir en sus dibujos el vocabulario en tsotsil, y aunque las palabras estaban escritas en la lámina que se encontraba pegada en el pizarrón argumentaban que no sabían hacerlo. Incluso una de ellas nos dijo que mejor les enseñáramos inglés. Otra niña mestiza dibujó la silueta de la cara, sin ojos ni boca y sin nariz; luego de insistirle, decidió trazar la boca y la nariz, pero no los ojos. Le preguntamos por qué había dibujado eso y nos comentó que su dibujo no tenía ojos porque era alguien que estaba ciego. Posiblemente, no quería dibujar todas las partes porque implicaba poner más palabras en lengua indígena.

También hubo actitudes de discriminación hacia la facilitadora hablante de tsotsil por parte de uno de los niños ladinos, quien al no ser atendido al momento que lo solicitaba, le gritó: “'no me entiendes, te tengo que hablar en tu lengua india?”. El maestro sugirió que lo mejor era expulsarlo definitivamente del taller, pero las facilitadoras le explicaron que lo pertinente era hablar con el alumno sobre lo que había ocurrido.

Tuvieron que pasar varios días para que dos de las niñas, una tseltal y otra tsotsil, decidieran escribir en su propio idioma. La presencia de una persona tsotsil que se dedicara a enseñarles cómo se escriben algunas palabras y la 


\section{A. Rodríguez y $M^{a}$ Elena Fernández ¿Aprender tsotsil? Experiencia...}

lectura en voz alta de los cuentos escritos en esta lengua fueron elementos que incidieron en el respeto entre los alumnos así como en el cambio de actitud. También el que las facilitadoras estuvieran interesadas en este idioma aborigen fue algo que motivó a los niños indígenas a compartirnos más palabras de las que veíamos en la clase. La directora nos compartió que de los años que llevaba al frente de la escuela nunca había escuchado hablar a los niños en su lengua, ni siquiera a la hora del recreo. Sin embargo, comentó que después de que inició el taller había escuchado a dos niñas del grupo hablar en tseltal durante el receso.

\section{Casos de resistencia}

El equipo llegó a la conclusión de que parte de los conflictos e incluso los problemas con la lectoescritura también son consecuencia de una baja autoestima que se manifiesta a través de la violencia escolar, tema que puede ser abordado en futuras investigaciones. Dentro del grupo, se detectaron casos de niños cuyas actitudes, demostradas hacia las actividades del taller, reflejaban ante los compañeros y los facilitadores muchas preocupaciones de carácter emocional así como situaciones relacionadas con problemas de aprendizaje.

El primer caso es de un niño de 10 años que nació en Pantelhó, su familia es ladina y hace algunos años migraron a San Cristóbal. Sus compañeros lo tenían catalogado como alguien que le gusta pelearse con los demás y el profesor lo consideraba como un niño problemático, por esta razón era tratado por la psicóloga de este centro educativo. Le interesaba ser el líder 


\section{A. Rodríguez y $M^{a}$ Elena Fernández ¿Aprender tsotsil? Experiencia...}

del grupo y controlar sobre todo a los niños. Las niñas se burlaban de él porque no sabía leer ni escribir, en respuesta, el niño les faltaba el respeto. Antes de iniciar el taller, la directora comentó que el diagnóstico de la maestra de la Unidad de Servicios de Apoyo a la Educación Regular (USAER) ${ }^{16}$ fue que el alumno "era de lento aprendizaje".

Durante las primeras sesiones de esta intervención educativa se pudo observar que leía despacio, y para escribir sus apellidos necesitaba ir por su libro o veía los trabajos de su hermana, quien estaba en el mismo grupo. También ofrecía dinero o alguna golosina a sus compañeros si le hacían las tareas, incluso ordenaba a su hermana que le hiciera sus trabajos escolares. Siempre demandaba tiempo para ser atendido de manera individual, y si no era escuchado en el momento que lo solicitaba se enojaba y cerraba su cuaderno. Se resistía a las actividades de escribir ya que no sabía hacerlo, se le apoyaba dictándole letra por letra, manifestando mucha creatividad en sus historias.

Una de las maestras formó un grupo para dar apoyo especializado a los niños que tenían mayores complicaciones con la escritura y las matemáticas, este niño asistió de manera constante. Pudimos observar que el alumno se sentía mucho más cómodo porque él y sus compañeros estaban en igualdad de condiciones, su actitud hacia las prácticas era positiva y entusiasta. Aunque

\footnotetext{
${ }^{16}$ La escuela tiene este servicio porque recibe como alumnos a niños con discapacidad. La directora de la escuela señalaba en una plática informal que si no aceptaran nińos con discapacidad no tendrían maestros de educación especial ni psicólogos para atender a los alumnos que necesiten terapias. Sin embargo, hace un mes que ya no cuentan con la maestra de esta unidad y las terapias se han suspendido.
} 


\section{A. Rodríguez y $M^{a}$ Elena Fernández ¿Aprender tsotsil? Experiencia...}

rechazaba las actividades relacionadas con el dibujo, diciendo que era para niños de "kínder" y que no servía para nada. También se sentía vulnerable ante las acusaciones del grupo por no saber leer y escribir, se sentía diferente y esto causaba de igual manera un conflicto; para expresarlo utilizó este tema en alguno de sus escritos: "Soy una hormiguita, como soy muy chica nadie me mira, me matan por ser tan chica, me pisotean, yo quisiera ser grande como el elefante, estoy muy triste”.

Otro niño tsotsil de 10 años también manifestó resistencia a las actividades. Le gustaba escuchar rap y presumía de trabajar con su abuelo en albañilería. Era considerado como un niño agresivo y recibía terapias de la psicóloga escolar. Al igual que el caso anterior, demandaba atención individualizada por parte de los facilitadores y si no se le brindaba en ese momento decidía no hacer las actividades del taller, o si ya había hecho parte del trabajo arrancaba las hojas de su cuaderno y las tiraba a la basura. Tampoco quería dibujar porque decía no saber hacerlo. No obstante, cuando platicaba con los facilitadores lo hacía con gusto y compartía sus experiencias previas antes de iniciar las lecturas.

Cuando se les propuso dibujar tarjetas para las mamás y escribir cartas para felicitar a los padres, él dijo que no lo haría porque no tenía mamá ni papá. Al preguntar con la directora sobre su situación, nos explicó que vivía con su abuelita porque había sido abandonado por su madre, quien había formado otra familia. Muchos de los niños que asisten a esta escuela sufren problemas familiares, como el abandono del padre por irse a Estados Unidos 


\section{A. Rodríguez y $M^{a}$ Elena Fernández ¿Aprender tsotsil? Experiencia...}

hasta la violencia intrafamiliar, temas que también podrían ser tratados en futuras investigaciones.

Figura 2: Fragmento de un cuento escrito por un niño ladino de Pantelhó

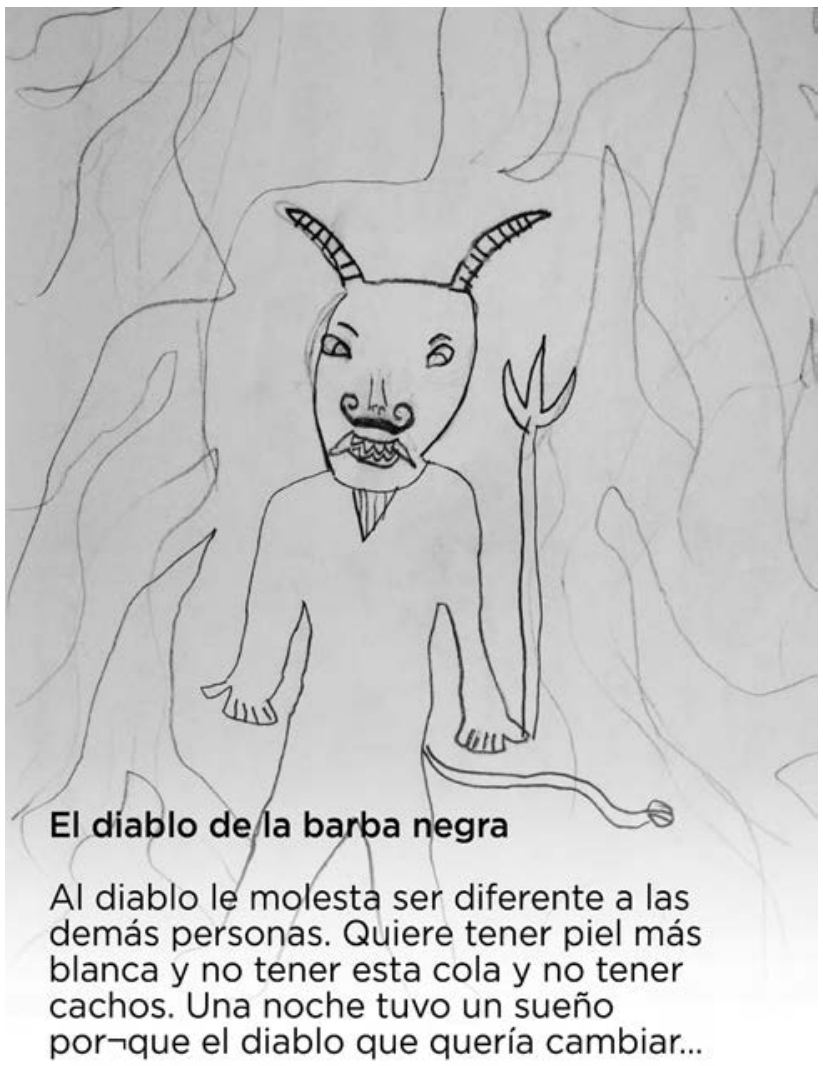

Fuente: Alejandra Rodríguez y María Elena Fernández Galán, 2013. 


\section{Algunas expresiones de sentimientos y valores encontrados en los cuentos}

Una manera de acercarse a los diversos intereses de los niños consistió en seleccionar algunos de sus escritos representativos de su manera de ver el mundo y la importancia en sus vidas de las relaciones humanas. De ahí que se escogieran entre los relatos espontáneos algunas manifestaciones de sus miedos, deseos y valores. La necesidad de conocer los intereses de los niños partió de la idea propuesta por Ferreiro (2002), quien indica que en el caso del desarrollo de la lectoescritura existe la dificultad de adoptar el punto de vista del niño, y ha resultado de tal magnitud que se han descuidado completamente las manifestaciones más evidentes de los intentos infantiles por comprender el sistema de escritura; los propios escritos de los niños.

Por su parte, Clemente (2008) señala que cuando se enseña a leer y escribir, el sentido funcional de esta actividad no puede quedar ajeno en el acto de aprender. Por ello es importante que quienes trabajan en la enseñanza de la lectoescritura reflexionen acerca de qué aspectos pueden ser valorados para que un niño desee aprender a leer y a escribir, no sólo como un requisito que debe cumplir para aprobar la escuela, sino pensar en un interés propio del alumno.

Sus cuentos reflejan influencias tanto de lo que han oído en sus casas como de algunos programas de televisión. Sin embargo la propuesta de que escribieran un sueño fue completamente libre, algunos se inclinaron por 


\section{A. Rodríguez y $M^{a}$ Elena Fernández ¿Aprender tsotsil? Experiencia...}

describir una pesadilla, otros un sueño representando sus miedos o sus deseos de un mundo mejor; una niña de inclinaciones muy religiosas describió un sueño con Dios. Las situaciones familiares estuvieron presentes en buena parte por las lecciones de tsotsil. Hay varias narraciones sobre la naturaleza y su cuidado por las reflexiones acerca de este tema que se observaron en las imágenes de las revistas. No obstante, aun cuando se organizaron actividades en torno a cuentos sobre el circo, la representación de una pastorela, el héroe Sipakná, ninguno de los cuentos escritos hace mención de estos temas. Cabe señalar que se hicieron correcciones de ortografía y estilo tratando de que los escritos no perdieran su esencia. De estos cuentos se escogieron algunos temas que nos parecen interesantes para conocer las preocupaciones dominantes dentro de la diversidad de historias.

En un grupo tan diverso encontramos más similitudes que diferencias, aunque se puede distinguir que los niños escribieron historias de acción y violencia, no así las niñas.

\section{a) Búsqueda de la felicidad}

La búsqueda de la felicidad y el sentirse contentos fueron temáticas muy presentes en los relatos de los niños, se citó 41 veces. Unos encontraban felicidad al poseer riquezas, otros al convivir con la familia y compartir la amistad: 


\section{A. Rodríguez y $M^{a}$ Elena Fernández ¿Aprender tsotsil? Experiencia...}

...Entonces me trajeron un traje parecido y elegante al que tenían ellas. Me invitaron a pasar a un cuarto muy bonito que tenía cuadros preciosos y allí me quedé a vivir y fui muy feliz.

\section{b) Amistad}

En cuanto al valor de la amistad se cuenta con 24 citas dentro de los cuentos, poesías y adivinanzas incluidos en la publicación Sueños, cuentos y dibujos (Fernández y Rodríguez, 2013). Se hace mención a quienes consideran malos amigos: no se deben ir diciendo chismes ya que eso significa ser mal amigo:

No importa quién soy. Desde cuándo quiero decirte que tus amigos dicen que tú caminas mal, tu pico está feo y tu cuerpo está horrible, tú nadas mal y además haces ruido... Y desde entonces, por los chismes del tiburón, ya no se volvieron a ver los amigos y también el tiburón chismoso se quedó sin amigos.

Todos los niños quieren hacer nuevos amigos, es muy importante conocer niños buenos:

¿ ¿Quieres ser mi amiga? La mariposa, al ver que la gatita era buena, le dijo que aceptaba ser su amiga. La gatita se sorprendió y así se hicieron amigas para siempre. 


\section{A. Rodríguez y $M^{a}$ Elena Fernández ¿Aprender tsotsil? Experiencia...}

\section{c) Familia}

En cuanto a la familia tomamos la figura de los padres, de la madre, del padre, y de los hermanos, solamente dos nińos mencionan a las abuelitas. La madre es muy importante, es la persona que cuida, apoya, y se preocupa por los niños. La palabra mamá aparece 40 veces mencionada. La madre nos enseña los primeros pasos, la madre es también maestra:

Era una mamá colibrí que acababa de tener sus hijos muy bonitos y después de unos días les enseñó a volar.

Siempre está latente el miedo de perder a la madre:

El cazador había matado a su mamá. En eso, el señor pensó: ¿Cómo le harán los hijitos de la osa para buscar comida?

Por su parte, se cita 24 veces la relación con el papá. La figura del padre es ambigua, se le puede tener un fuerte rechazo pero a la vez el abandono del padre hace sufrir a los hijos. Por ejemplo, el miedo a un seńor que dice ser el padre pero no se sabe si tiene buenas o malas intenciones:

...-Soy yo, tu padre. Y ella le dijo: -No lo conozco a usted, a lo mejor usted me querrá vender. Y el señor le dijo: -No, no, soy tu padre, vine para que me conozcas mejor. 


\section{A. Rodríguez y $M^{a}$ Elena Fernández ¿Aprender tsotsil? Experiencia...}

Hay una gran inquietud de parte de los hijos para que sus papás les hagan caso:

Un día sus papás tuvieron un día de descanso. La niña le dijo a sus padres que salieran a jugar y su papá le respondió: - ¿No ves que estoy muy cansado? La niña se puso a llorar y le dijo a su papá: -¿Por qué no me hacen caso?...

Las referencias sobre la relación con hermanos cuentan 25 citas. Ejemplo de ello es cuando los hermanos se apoyan unos a otros:

...Yo sońé que un día mi mamá me dijo que yo le lavara su pie de mi hermanito antes de que se fuera a dormir. Era de noche cuando salí al lavadero del patio a lavarle su pie de mi hermanito. A mi mamá le gusta plantar milpa, frijol, chile y rosas en el patio. Entonces salió mi hermanita Ruti...

d) Amor

Por otro lado, tanto niñas como niños están interesados en las relaciones de pareja quizá porque están pasando a la etapa de la pubertad. Estar acompañados es muy importante; encontrar a alguien con quien compartir. Esto fue reflejado en sus cuentos, donde aparecen 21 citas referentes a los novios, esposos o enamorados. Muchos escriben sobre enamorados buscando felicidad: 


\section{A. Rodríguez y $M^{a}$ Elena Fernández ¿Aprender tsotsil? Experiencia...}

Los canguros enamorados comían frijol y lo repartían con sus demás amigos que se encontraban en el camino...

e) Tristeza

La tristeza se citó 20 veces, sin embargo en muchos cuentos, aun cuando no se menciona la palabra, estaba presente el miedo a sentirse tristes. La pérdida de hijos, amigos, siempre es causa de mucha tristeza:

La mamá se fue muy triste de esa cabaña sin su hijita.

\section{f) Muerte}

En relación con los sentimientos, los niños expresaron en los cuentos la muerte y el miedo a lo desconocido. Los muertos tuvieron presencia en los escritos:

...Me llamo el Muerto Viviente, entrégame tu alma, tu alma es mía de por vida, tu corazón te lo sacaré por mi cuenta...

\section{g) Religiosidad}

Una de las alumnas constantemente preguntaba la adscripción religiosa de los facilitadores, la importancia que tiene esto en su vida se vio plasmada en uno de sus cuentos:

Les voy a contar mi sueño: yo soñé que venía Dios en los cielos y que nos llevaba al cielo a todos. Pero no todos, se quedaron los malos, los que no creían en Dios. Dios nos dijo que iba a hacer un nuevo mundo pero salió el diablo para detenernos y agarró a mi abuelita. 


\section{A. Rodríguez y $M^{a}$ Elena Fernández ¿Aprender tsotsil? Experiencia...}

De pronto un ángel de luz la rescató del pozo de fuego. Dios elevó su mano e hizo una burbuja gigante y nos protegió de la pura maldad.

h) Maestros y escuela

Muy pocos niños manifestaron en los cuentos un interés especial por la escuela:

De repente, vio que a un su amigo lo comió el lobo y a tres maestros

los comieron los muertos que salieron del panteón.

Figura 3: Adivinanzas escritas en tseltal por Martha, nińa originaria de Tenejapa

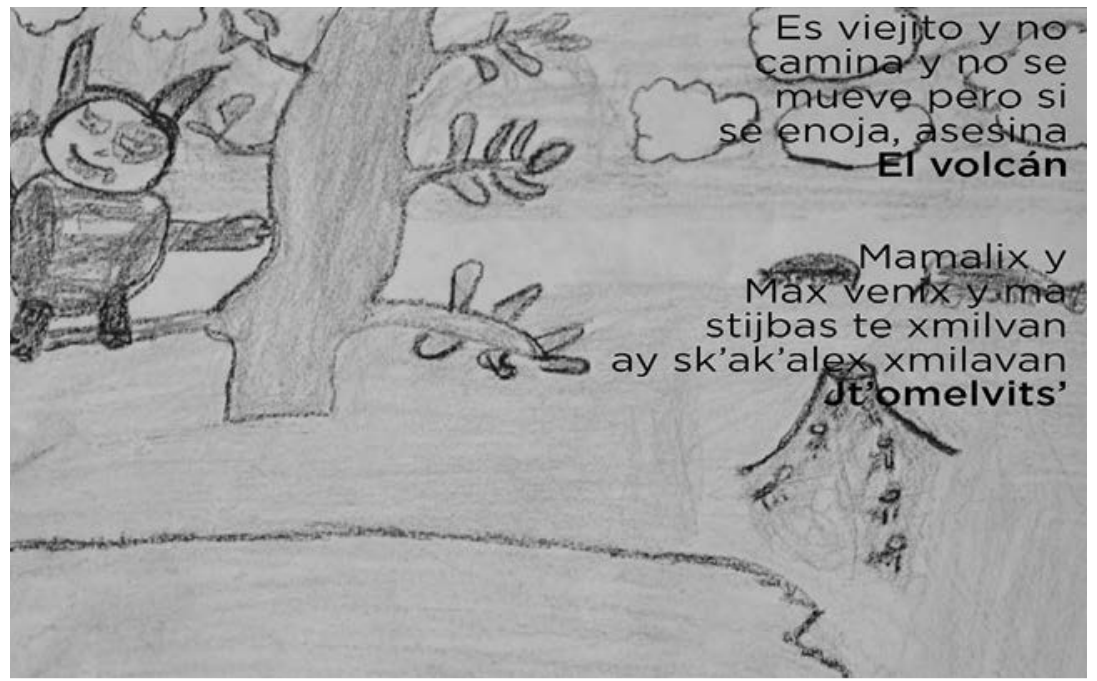

Fuente: Alejandra Rodríguez y María Elena Fernández Galán, 2013. 


\section{A. Rodríguez y $M^{a}$ Elena Fernández ¿Aprender tsotsil? Experiencia...}

\section{Evaluación del taller: la mirada de los propios niños}

Parte esencial del proceso de evaluación del taller consistió en que los niños expresaran su percepción sobre lo sucedido, saber qué actividades habían sido significativas para ellos, qué les había gustado y cómo se sintieron durante el taller. Es necesario aclarar que no se realizaron entrevistas directas a los niños porque el grabarles en audio podría resultarles intimidante. Por ello, preferimos recurrir a sus escritos espontáneos, en los cuales plasmaron libremente su opinión. Reconocemos que nuestro análisis es limitado y que habría que incluir otros aspectos para realmente conocer la mirada de los niños, sin embargo es un punto de partida interesante que puede abrir mayores posibilidades de investigación y estudio.

Para ello, les planteamos que hicieran una carta dirigida al maestro Clodoveo Malo, encargado de facilitar los recursos del proyecto para esta intervención educativa. En ella los niños escribieron sus opiniones, sellaron los sobres y los decoraron. Las cartas fueron entregadas al maestro Clodoveo, una vez que fueron leídas decidió compartirnos el contenido de estos escritos. Resultado de ello, se obtuvo que la actividad favorita fue el dibujo, especialmente con pinturas (doce citas):

A mí me gustó dibujar en pintura, las adivinanzas, jugar a la cuerda y a la lotería. 


\section{A. Rodríguez y $M^{a}$ Elena Fernández ¿Aprender tsotsil? Experiencia...}

El escribir en las computadoras fue citado por nueve nińos. Esto tuvo mucha relevancia debido a que la mayoría usó por primera vez en su vida una computadora:

Me gustó lo de la pantalla porque los botones del teclado me ayudaron a poner mi nombre, me gustó mucho. Me gustó trabajar en la computadora, manejar el ratón y el teclado [esto lo escribió una de las niñas que al principio del taller no sabía escribir].

Asimismo, los niños valoraron mucho los juegos que se realizaron al finalizar el taller, principalmente saltar la cuerda y jugar lotería (nueve citas):

Me gustó el taller porque cuando terminamos de escribir salíamos a jugar al patio con las maestras.

También expresaron su gusto por la lectura de cuentos y cómics (nueve citas):

Yo me gustaría que regresen otra vez las maestras, también me gustaría leer los cómics.

El teatro fue una estrategia que ayudó considerablemente por la confección de los trajes y máscaras (ocho citas):

Recuerdo cuando hicimos la pastorela que fue lo que más me gustó, hicimos máscaras, costuramos las telas para la pastorela. 


\section{A. Rodríguez y $M^{a}$ Elena Fernández ¿Aprender tsotsil? Experiencia...}

Los niños agradecieron el hacer cosas diferentes a lo que normalmente están acostumbrados en la escuela:

Lo que hicimos fue fabuloso, maravilloso porque salimos a jugar, a pintar, y muchas cosas más.

Me gustó porque son actividades distintas a las cosas normales, ya que aprendí cosas nuevas y a la vez me divertí mucho.

Los niños indicaron también que les gustó aprender a escribir y leer tsotsil (4 citas):

Me ayudó mucho en mi escritura y lectura al igual aprendí palabras en tsotsil.

Me gustó de la pastorela, de las poesías y de las lecturas en tsotsil, y también me gustó de las cartas.

Por último, escribieron que se sentían contentos por lo aprendido en el taller (4 citas) y que se habían divertido (6 citas); la mayoría expresó su deseo de que las facilitadoras llevaran a cabo otro taller cuando estuvieran en quinto grado:

Me la pasé muy bien, aprendí mucho y quiero que vuelvan el otro año, por favor. 


\section{A. Rodríguez y $M^{a}$ Elena Fernández ¿Aprender tsotsil? Experiencia...}

\section{Consideraciones finales}

Las ciudades están formadas por la convergencia de personas de origen diverso. México es un país donde se congrega un mosaico de culturas que conviven en el mismo espacio, aun sabiendo que cada región, territorio y ciudad presentan condiciones diferentes y adaptaciones únicas. San Cristóbal no es la excepción, se conformó con habitantes indígenas nativos del lugar, tlaxcaltecas y mexicanos llegados con los españoles a los que se les ha venido agregando un sinfín de personas.

En el ámbito de la educación, la escuela primaria presenta un conflicto escolar, ya que la intención de la educación formal es legitimar la cultura nacional y dejar fuera las culturas minoritarias. Las leyes y los discursos políticos reconocen que en el país existe la diversidad y aparentemente se fomenta la educación "intercultural” para estar acorde con los parámetros internacionales de la Unesco, pero en la práctica el sistema educativo sigue un multiculturalismo relativo tendiente a la asimilación de la cultura nacional. El sistema educativo mexicano es centralista, ya que en los programas se ignora que existen grupos con historias socioculturalmente diferentes de la nacional. Las políticas educativas excluyen los procesos propios de pensamiento y comunicación de cada cultura local; la dificultad de los maestros de llegar a comprender a cada grupo los obliga a ajustarse a un modelo educativo diseñado para hispanohablantes del centro de la república. 


\section{A. Rodríguez y $M^{a}$ Elena Fernández ¿Aprender tsotsil? Experiencia...}

El grupo de niños con quienes se organizó el taller reflejó el encuentro de varias culturas con diferencias en el idioma, ya que había niños procedentes de comunidades tseltales y tsotsiles, además el dialecto del español de niños de comunidades ladinas. Estos niños se enfrentan a la expresión del castellano de los libros de texto y de los maestros. Por otro lado, los credos viejos y nuevos surgidos en San Cristóbal han sido motivo de pequeñas disputas entre las niñas "cristianas" de varias denominaciones, tradicionalistas y católicos.

Los niños de este grupo no estaban motivados en estudiar, no se identificaban ni como grupo, ni con los programas ni con las prácticas, lo que los llevaba a un rechazo sistemático de las actividades escolares y a una convivencia complicada. La tarea de convencer a todos y a cada niño de sus posibilidades intrínsecas para aprender, valorar su imaginación y respetar posturas, valores e intereses fue posible al implementar actividades diferentes a las prácticas escolares cotidianas, a la atención personalizada y el estimular cada esfuerzo individual.

La propuesta de aprender tsotsil, por ser la lengua indígena más hablada en la ciudad, despertó el rechazo de los niños ladinos, particularmente de los niños procedentes de comunidades en donde conviven ladinos e indígenas.

¿Aprender tsotsil? A los chiapanecos, que han interiorizado la supremacía del español y todo lo que esto conlleva, es tarea difícil llegar a convencerlos del valor de las lenguas indígenas y de su riqueza. El aprendizaje del tsotsil es tan importante como aprender historia o geografía, las palabras 


\section{A. Rodríguez y $M^{a}$ Elena Fernández ¿Aprender tsotsil? Experiencia...}

de un idioma conforman un sistema de pensamiento que ayuda a desarrollar el conocimiento.

La adquisición de la lectoescritura en tsotsil consiguió efectos positivos para la convivencia del grupo de niños de una primaria de San Cristóbal. Se logró la aceptación del aprendizaje de este idioma y se consiguió producir un libro con una colección de los mejores escritos de los alumnos con cuentos, poesías y adivinanzas, muchos de ellos en tsotsil. En este librito es sorprendente encontrar la diversidad de temas escogidos por los nińos, a pesar de que todos ven televisión, las narraciones no están circunscritas en torno a los programas que emiten. En cuanto a la tradición, por ejemplo muchos niños escribieron acerca de la leyenda de La Llorona, pero cada Llorona fue diferente.

Quedan muchas tareas pendientes con las que llegar a conocer lo que piensan los niños en ambientes de encuentros culturales, tanto acerca de las maneras como aprenden a leer y a escribir como sobre el respeto a las personas, a las lenguas y a las culturas diferentes. Existe la posibilidad real de lograr la equidad y el equilibrio entre culturas necesarios para la formación integral de los nińos, no solamente en las escuelas bilingües sino que todos los programas escolares contengan el planteamiento de la diversidad del país.

Se necesitarán nuevos estudios sobre la educación en ambientes urbanos donde coexisten diferentes culturas para poder realmente incidir en la educación intercultural. Asimismo, el implantar estrategias que permitan la estrecha colaboración de maestros, padres de familia, alumnos y de la sociedad sancristobalense con el fin de lograr una convivencia mejor, 


\section{A. Rodríguez y $M^{a}$ Elena Fernández $\quad$ ¿Aprender tsotsil? Experiencia...}

una verdadera educación intercultural, así como fomentar la proliferación de escritos en lenguas indígenas que además de conservar la lengua le otorguen el prestigio que les corresponde.

Figura 4: Fragmento de un cuento que desarrolla el tema de la amistad

\section{El Bolom y la Pepen}

La mariposa, que se llamaba Pepen, tenía miedo porque ella sabe que los gatos comen insectos y mariposas... En eso, la gatita Bolom le dijo a la mariposa: ¿Quieres ser mi amiga?

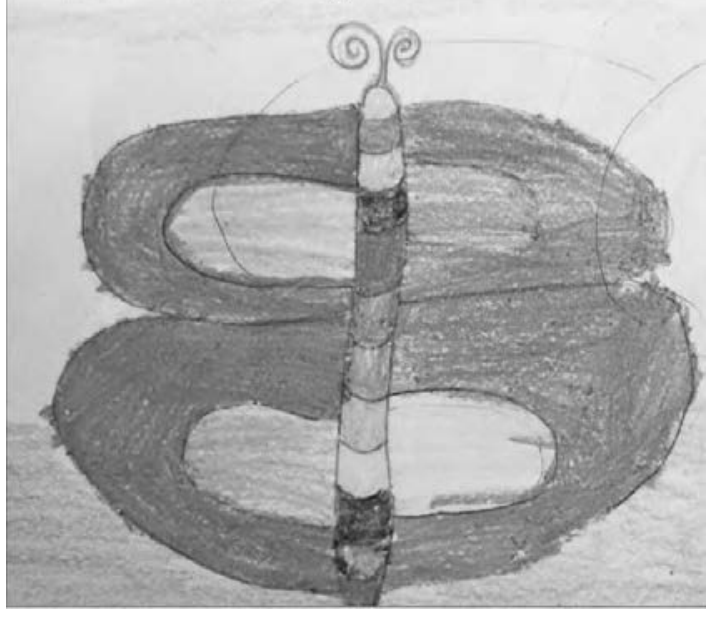

Fuente: Alejandra Rodríguez y María Elena Fernández Galán, 2013. 


\section{Bibliografía citada}

Aguirre Beltrán, Gonzalo, 1983, Las lenguas vernáculas: su uso y desuso en la enseñanza: la experiencia de México, CIESAS, México.

Bertely, María, 2013, “Apropiación étnica e intermediación académica. Una experiencia de educación intercultural alternativa en y desde Chiapas", en Ascencio, Gabriel (coordinador), Teoría y práctica de la educación intercultural en Chiapas, Proimmse IIA UNAM, San Cristóbal de Las Casas, Chiapas, pp. 139-154.

Clemente, María, 2008, Enseñar a leer: bases teóricas y propuestas prácticas, Pirámide, Madrid.

Fernández Galán, María Elena, 2010, "Entre la fidelidad y la necesidad: muestra del uso de las lenguas indígenas en San Cristóbal", en Anuario de Estudios Indigenas 14, IEI Unach, San Cristóbal de Las Casas, Chiapas, pp. 43-68.

Fernández Galán, María Elena y Alejandra Rodríguez (coordinadoras), 2013, Sueños, cuentos y dibujos, IEI Unach, Innovación y Apoyo Educativo, San Cristóbal de Las Casas, Chiapas.

Ferreiro, Emilia, 1996, "Diversidad y proceso de alfabetización: de la celebración a la toma de conciencia", en Revista Latinoamericana de Lectura (Lectura y Vida), vol. 15, núm. 3, pp. 5-14.

Ferreiro, Emilia, 2002, Alfabetización: teoría y práctica, Siglo XXI, México.

Freedson González, Margaret y Elías Pérez Pérez, 1999, “El uso de los libros nacionales y de la lengua indígena en la práctica docente bilingüe", en La educación bilingüe-bicultural en Los Altos de Chiapas. Una evaluación, SEP, México, D.F

García Canclini, Néstor, 2004, Diferentes, desiguales y desconectados: mapas de la interculturalidad, Gedisa, México.

Gobierno del estado de Chiapas, 2013, Plan estatal de desarrollo: Chiapas 2013-2018, Gobierno del estado de Chiapas, Tuxtla Gutiérrez, Chiapas, disponible en http://www.ped.chiapas.gob.mx/ped/ [fecha de consulta: 14 de abril de 2014]. 
Hvostoff, Sophie, 2009, "La comunidad abandonada. La invención de una nueva indianidad urbana en las zonas periféricas tzotziles y tzeltales de San Cristóbal de Las Casas, Chiapas, México (1974-2001)”, en Estrada Saavedra, Marco (editor), Chiapas después de la tormenta, El Colegio de México, Gobierno del estado de Chiapas, México, pp. 221-278.

Instituto Nacional de Estadística, Geografía e Informática, 2010, Censo de Población y Vivienda 2010, México.

Modiano, Nancy, 1974, La educación indígena en Los Altos de Chiapas, Instituto Nacional Indigenista, Secretaría de Educación Pública, México.

Paniagua Mijangos, Jorge Gustavo, 2014, Diversidad urbana y ciudad. Una perspectiva antropológica, IEI Unach, San Cristóbal de Las Casas, Chiapas.

Pons Bonals, Leticia, 2001, "Actitudes lingüísticas de jóvenes tzeltales que se incorporan a escuelas (del nivel medio) en la ciudad de San Cristóbal de Las Casas", en Sombra de Papel, Revista de la Coordinación de Investigación y Posgrado de la Facultad de Humanidades, UNACH, año 1, núm. 3, pp. 7-53.

Rodari, Gianni, 1999, Gramática de la fantasía: introducción al arte de inventar historias, Panamericana, Santafé de Bogotá.

Rus, Jan, 2009, "La nueva ciudad maya en el valle de Jovel: de una nueva indianidad urbana en las zonas periféricas tzotziles y tzeltales de San Cristóbal de las Casas", en Estrada, Marco (editor), Chiapas, después de la tormenta: estudios sobre economía, sociedad y politica, El Colegio de México, México, pp. 169-220.

Saldívar, Antonio, 2005, "Educación e interculturalidad. Retos de la educación indígena en México y Guatemala", en Ángeles, Hugo, Laura Huicochea, Antonio Saldívar y Esperanza Tunón (coordinadores), Actores y realidades en la frontera sur de México, Ecosur, Coespo, Tuxtla Gutiérrez, Chiapas, pp. 307-331. 